\title{
THE ORNITHOMORPHS OF THE MUSEUM OF ARCHAEOLOGY AND ETHNOGRAPHY OF CHELYABINSK STATE UNIVERSITY AND THE CENTER OF HISTORICAL AND CULTURAL HERITAGE OF CHELYABINSK
}

\author{
Ilya E. Liubchanskiy \\ Center of Historical and Cultural Heritage of Chelyabinsk, Chelyabinsk, Russian Federation \\ Vladimir I. Yurin \\ Center of Historical and Cultural Heritage of Chelyabinsk, Chelyabinsk, Russian Federation
}

\begin{abstract}
This article publishes new archaeological materials that came to the Museum of Archaeology and Ethnography of Chelyabinsk State University and the Center of Historical and Cultural Heritage of Chelyabinsk in 2015-2017. Materials of so-called "hoards" of ornithomorphs are extremely rare in the Northern areas of the Southern Trans-Urals. Therefore, the discovery of new objects of small bronze sculpture in storage facilities is of great scientific interest. The main area of distribution of "hoards" is connected with the territory of the forest-steppe zone of the Middle Urals, where the "settlements" and "sanctuary" complexes of Itkul culture of the $6^{\text {th }}-3^{\text {rd }}$ centuries BC were located. Finding ornithomorphs in the forest-steppe zone of Chelyabinsk region extends the border of the influence of Itkul archaeological culture carriers far to the South. Ornithomorphs are traditionally associated with religious beliefs of Itkul culture carriers. As a rule, ornithomorphs are found in places where ancient "sanctuary" complexes were located: on mountain tops, in rocks or at the foot. In our case, the findings came from areas where there are no mountains or mountain outliers. These findings are from the cape hills of the South Ural lakes. The random detection of ornithomorph collection, unfortunately, does not allow to accurately determine the location of the "sanctuary" complexes. It allows to determine only the area of their approximate location. The article provides a detailed description of ornithomorphs and proposes their typology. The collection includes a variety of ornithomorphs, which can be attributed to six typological groups, and their transitional forms can be allocated. Finding a bronze arrowhead allows us to offer a conditional dating of "hoards" within the $4^{\text {th }}$ century BC.
\end{abstract}

Key words: ornithomorphs, small bronze sculpture, Itkul culture, the early Iron Age of the Southern Trans-Urals.

Citation. Liubchanskiy I.E., Yurin V.I., 2019. The Ornithomorphs of the Museum of Archaeology and Ethnography of Chelyabinsk State University and the Center of Historical and Cultural Heritage of Chelyabinsk. The Lower Volga Archaeological Bulletin, vol. 18, no. 1, pp. 138-148. (in Russian). DOI: https://doi.org/10.15688/ nav.jvolsu.2019.1.11

\section{«ПТИЦЕГОЛОВЫЕ ИДОЛЫ» ИЗ ФОНДОВ МУЗЕЯ АРХЕОЛОГИИ И ЭТНОГРАФИИ ЧЕЛЯБИНСКОГО ГОСУДАРСТВЕННОГО УНИВЕРСИТЕТА И ЦЕНТРА ИСТОРИКО-КУЛЬТУРНОГО НАСЛЕДИЯ Г. ЧЕЛЯБИНСКА}

\author{
Илья Эдуардович Любчанский \\ Центр историко-культурного наследия г. Челябинска, г. Челябинск, Российская Федерация
}


И.Э. Любчанский, В.И. Юрин. «Птицеголовые идолы» из фондов Музея археологии и этнографии

\section{Владимир Иванович Юрин}

Центр историко-культурного наследия г. Челябинска, г. Челябинск, Российская Федерация

Аннотация. Настоящая статья посвящена публикации новых археологических материалов, которые поступили в фонды Музея археологии и этнографии Челябинского государственного университета и Центра историко-культурного наследия г. Челябинска в 2015-2017 годах. Материалы так называемых «кладов» орнитоморфов или «птицеголовых идолов» весьма редки на территории северных районов Южного Зауралья. Поэтому обнаружение в фондохранилищах новых предметов мелкой бронзовой пластики представляет научный интерес. Основной ареал распространения «кладов» связан с территорией лесостепи Среднего Урала, где располагались «городища» и «святилищные» комплексы иткульской культуры VI-III вВ. до н.э. Нахождение «птицеголовых идолов» в лесостепной зоне Челябинской области расширяет далеко на юг границу распространения влияния носителей иткульской археологической культуры. Орнитоморфы или «птицеголовые идолы» традиционно связываются с религиозными представлениями носителей традиций иткульской культуры. Как правило, они обнаруживаются на местах, где располагались древние «святилищные» комплексы на вершинах гор, в скалах или у подножия. В нашем случае находки поступали из районов, где нет гор или горных останцов. Данные находки происходят с мысовых возвышенностей южноуральских озер. Случайность обнаружения коллекции орнитоморфов, к сожалению, не позволяет точно установить местонахождение «святилищных» комплексов, а только район примерного их расположения. В статье приводится подробное описание орнитоморфов. Предлагается их типология. В коллекции собраны разнообразные орнитоморфы, которые можно отнести к шести типологическим группам, а также выделить переходные формы. Нахождение бронзового наконечника стрелы позволяет предложить условную датировку «кладов» в пределах IV в. до н.э.

Ключевые слова: «птицеголовые идолы», орнитоморфы, мелкая бронзовая пластика, иткульская культура, ранний железный век Южного Зауралья.

Цитирование. Любчанский И. Э., Юрин В. И., 2019. «Птицеголовые идолы» из фондов Музея археологии и этнографии Челябинского государственного университета и Центра историко-культурного наследия г. Челябинска // Нижневолжский археологический вестник. Т. 18, № 1. С. 138-148. DOI: https://doi.org/10.15688/ nav.jvolsu.2019.1.11

В конце 2017 г. в фонды Музея археологии и этнографии Челябинского государственного университета был передан случайно обнаруженный «клад» орнитоморфов («птицеголовых идолов») в количестве 15 фигурок и одного наконечника стрелы. Тогда же во время работы с фондом случайных находок Центра историко-культурного наследия г. Челябинска были обнаружены еще три фигурки орнитоморфов. Обстоятельства находки «клада» и его точного месторасположения не известны. Приблизительное местонахождение орнитоморфов связано с одним из озер близ д. Аминева Кунашакского района Челябинской области. Из сохранившейся записки, найденной в упаковке с тремя орнитоморфами, становится известно, что они обнаружены на территории бывшей деревни Сапхангулово Аргаяшского района Челябинской области примерно в 300 м от западного берега озера Малый Кисегач. На суд научной общественности выносится описание всех 18-ти фигурок. Также авторами предпринимается попытка группировки фигурок по их морфологическим и орнаментальным особенностям.

\section{Описание фигурок-орнитоморфов}

Фигура 1 (рис. 1,1).

Литье, бронза. Изделие бракованное. Сохранилась полностью необработанная часть правого плеча. Фигура с лицевой стороны объемная, с тыльной стороны - плоская, что позволяет говорить об использовании при производстве одностворчатой формы для литья. На лицевой стороне изделия имеется орнамент в виде сложной геометрической фигуры, которая имитирует хвостовое оперение. На левом, хорошо сохранившемся крыле, имеется 11 объемных валиков, которые расположены параллельно, по всей длине крыла. Туловище фигуры расширяется к нижней части. Хорошо выражены плечи и шея. Правое крыло утрачено. Размеры изделия составили: общая длина - 6,2 см; длина крыла 3,8 см; длины плеч - по 1,5 см соответственно; ширина шеи - 0,5 см; ширина тулова у плеч - 1,0 см, ширина тулова внизу $-1,3$ см. Нижняя часть частично повреждена и, видимо, имела округлую форму. Сохранность изделия удовлетворительная. 
Фигура 2 (рис. 1,4).

Литье, бронза. У изделия сохранились необработанные элементы шеи и крыльев. Фигура объемная с плоской спинкой. Изделие после отливки не было обработано. На лицевой поверхности сохранились щербинки от литейного производства (лопнувшие пузырьки воздуха). Здесь же, на лицевой стороне, имеется объемный орнамент, который, возможно, изображает согнутые лапы хищной птицы или «птицевидного» существа. Слабовыраженное фасетирование подчеркивает расширение изделия к его окончанию. Сохранившееся левое крыло имеет три волны, которые имитируют оперение. Из-за плохой сохранности правого крыла увидеть наличие таких же волн не представляется возможным. Нижняя часть изделия закруглена, отчетливо выражены шея и плечи фигуры. Мускульность фигуры подчеркивается фасетированием. Размеры фигуры: длина 6,6 см; длина левого крыла - 5,0 см; длина правого крыла - 4,5 см; высота шеи - 1,2 см; ширина шеи - 0,6 см; ширина тулова $-1,2$ см; максимальная ширина тулова $-1,5$ см; высота орнамента - 2,0 см; размах плеч 2,5 см (по внутренней части). Сохранность удовлетворительная, но требует первичной консервации.

Фигура 3 (рис. 1,5).

Литье, бронза. Сохранились необработанные части крыльев. Фигура объемная, с плоской спинкой. Изделие не обработано, тулово изделия расширяется к его окончанию, имитируя хвост птицы. На теле сохранился объемный орнамент в виде «согнутых лап хищной птицы». Объем подчеркивается фасетированием части тулова изделия. Окончание тулова изделия треугольное, на левом крыле видна имитация перьевого оперения в виде трех волн, отчетливо выражены шея и плечи фигуры. Наличие мускул слабо выражено. Размеры фигуры: длина - 7,0 см; длина левого крыла - 5,0 см; длина правого крыла 5,0 см; ширина шеи - 1,0 см; высота шеи 1,5 см; ширина тулова $-1,0$ см; максимальная ширина тулова $-1,8$ см; высота орнамента $-2,0$ см; размах плеч $-2,5$ см (по внутреннему контуру). В целом сохранность удовлетворительная, но требует первичной консервации и реставрации.
Фигура 4 (рис. 1,6).

Литье, бронза. Фигура объемная, с плоской спинкой. Изделие имеет следы финальной обработки. Тулово изделия плавно расширяется к низу, и, видимо, плавно закруглялось. Часть окончания фигуры обломано. На тулове имеется четкий, объемный орнамент в виде «согнутых лап хищной птицы». На левом и правом крыле отчетливо видны имитации оперенья. У изделия оказались необработанными верхние окончания крыльев. Наличие объемных мускул подчеркивается широтой плеч. Размеры фигуры: длина - 7,5 см; длина левого крыла - 5,1 см; правого крыла - 4,5 см; ширина шеи - 0,6 см; высота шеи - 1,5 см; ширина тулова - 1,1 см; максимальная ширина тулова - 1,5 см; высота орнамента - 2,1 см; размах плеч $-2,5$ см (по внутреннему контуру). Сохранность удовлетворительная. На правом плече появляются сульфатные «звездочки». Нужна консервация и частичная реставрация.

Фигура 5 (рис. 1,9).

Литье, бронза. Изделие в виде «птицевидного идола», простое в исполнении. Фигура объемная, с плоской спинкой. Четко выражены все отделы: шея, правое и левое крыло, которые примыкают к тулову под острым углом. Тулово практически прямое. По длинным сторонам расположены слабовыраженные фасетки. На теле фигуры присутствует объемный орнамент в виде пяти валиков, которые очерчивают область шеи и тулова. Размеры фигуры: длина $-8,1$ см; длина левого крыла с литником $-4,7$ см; длина правого крыла с литником $-4,4$ см; ширина шеи варьирует в пределах 0,5-0,6 см; высота шеи - 2,1 см; ширина тулова $-1,0$ см; максимальная ширина тулова $-1,3$ см; размах плеч $-2,7$ см. Сохранность изделия удовлетворительная, но требует первичной консервации.

Фигура 6 (рис. 2,2).

Литье, бронза. На изделии читается стилизованная голова птицы. Также подработаны верхние части крыльев. Шея хорошо выражена. Тулово незначительно расширяется к нижнему окончанию, которое, видимо, было первоначально округлым. Часть его повреждена. На лицевой стороне тулова две волны на левом крыле имитируют оперение, на правом крыле такая же имитация оперения, только с внешней стороны. Крылья к плечам под- 
ходят под прямым углом. Размеры фигуры: длина $-6,8$ см; длина левого крыла $-3,8$ см; длина правого крыла $-3,7$ см; ширина шеи 0,5 см; высота шеи - 0,7 см; ширина тулова 0,9 см; максимальная ширина тулова $-1,4$ см; высота орнамента - 2,0 см; размах плеч 2,5 см. Сохранность удовлетворительная. Для изделия требуется первичная консервация.

Фигура 7 (рис. 1,3).

Литье, бронза. Хорошо выражена стилизованная головка птицы. Фигура объемная, с плоской спинкой. Левое крыло длинное, узкое и тонкое. На нем сохранилось 7 валиков, имитирующих оперение крыла птицы. Правое крыло обломано, от него сохранилась только треть. В центральной части тулова сохранился объемный орнамент в виде «пояса с отстоящим наконечником». В нижней части тулова имеется отверстие, ее пытались подработать. Крылья подходят к плечам под прямым углом. Размеры фигуры: длина - 6,5 cм; длина левого крыла $-4,0$ см; длина правого крыла $-1,5$ см; ширина шеи $-0,7$ см; высота шеи $-0,6$ см; ширина тулова $-1,0$ см; максимальная ширина тулова $-1,6$ см; размер орнамента $-0,8 \times 1,0 \mathrm{~cm}$; размах плеч $-2,6 \mathrm{~cm}$. На оборотной стороне изделия имеется щербинка от воздушного пузыря. Сохранность удовлетворительная. Требуется первичная консервация.

Фигура 8 (рис. 1,10).

Литье, бронза. Крылья к тулову подходят по дуге под острым углом. Тело изделия прямое, фасетированное. Шея округлая, длинная. На теле имеется рельефный орнамент из четырех объемных валиков, которые расположены перпендикулярно оси изделия. Спинка изделия плоская и тонкая. Размеры фигуры: длина - 7,6 см; длина левого крыла 4,3 см; длина правого крыла $-3,5$ см; ширина шеи - 0,5-0,6 см; высота шеи - 2,1 см; ширина тулова $-1,0$ см; максимальная ширина тулова - 1,0 ; размер орнамента $-2,2 \mathrm{cm;} \mathrm{размах}$ плеч $-2,5$ см. Литник правого крыла обработан и превращен в стилизованный «шип» крыла. Сохранность изделия удовлетворительная, но необходима первичная консервация.

Фигура 9 (рис. 1,2).

Литье, бронза. У изделия имеется необработанная часть, которая примыкает к правому крылу. Хорошо выражена шея, сохранились два крыла, на которых имеются объемные валики в количестве 11 штук на каждом. Эти валики передают стилизованное оперение фигуры. На лицевой стороне тулова имеется сложный геометрический орнамент, который подчеркивает объемность хвостового оперенья идола. Крылья примыкают к плечам под прямым углом. Нижняя часть тулова фигуры, скорее всего, была округлая. Размеры изделия: длина $-6,5$ см; длина левого крыла $-3,5$; длина правого крыла $-4,0$ см; ширина шеи 0,7 см; высота шеи - 0,8 см; ширина тулова 0,9 см; максимальная ширина тулова $-1,3$ см; размах плеч $-2,6$ см. Сохранность изделия удовлетворительная, но требуется первичная консервация.

Фигура 10 (рис. 1,7).

Литье, бронза. Изделие объемное, с плоской спинкой. Отливка изделия производилась в одностворчатой форме. Хорошо выражена шея, сохранились крылья, которые подходят к плечам под прямым углом. Тулово изделия птицевидное, округлое внизу и приталенное возле плеч. На тулове имеется объемный орнамент в виде «лап хищной птицы». На крыльях имеется по три волны, которые подчеркивают наличие стилизованного оперения. Размеры изделия: длина $-7,0$ см; длина левого крыла $-4,8$ см; длина правого крыла 4,0 см; ширина шеи - 0,6 см; высота шеи 1,7 см; ширина тулова - 1,0 см; максимальная ширина тулова - 1,5 см; размер орнамента $-2,0$ см; размах плеч $-2,5$ см. Сохранность удовлетворительная. Требуется первичная консервация.

Фигура 11 (рис. 2,3).

Литье, бронза. Шея высокая, тулово расширяется книзу. Крылья подходят к плечам под прямым углом. На тулове и крыльях расположен объемный и фигурный орнамент. Оперение крыльев обозначается «пиловидными» зубцами, которые переходят в валики на поверхности крыльев. На тулове, в грудной части, хорошо виден киль птицы, оперенье изображено в виде «елочки», а лапы птицы выполнены в виде двух округлых «жемчужин». Размеры изделия: длина - 7,2 см; длина левого крыла - 3,6 см; длина правого крыла 3,9 см; ширина шеи - 0,6 см; высота шеи 1,5 см; ширина тулова - 1,4 см; максимальная ширина тулова - 1,8 см; размер орнамен- 
та - 4,4 см; размах плеч - 2,7 см. Сохранность удовлетворительная. Требуется первичная консервация.

Фигура 12 (рис. 2,1).

Литье, бронза. Тулово изделия фасетировано и расширяется к низу, имитируя хвост птицы. На плечах имеются шипы - на левом 1 шип, на правом 2 шипа соответственно. Левое крыло подходит к плечу под прямым углом, правое - под острым углом и по дуге. Стилизация оперения на левом крыле представлена в виде одинокой волны. Размеры изделия: длина $-8,7$ см; длина левого крыла 4,5 см; длина правого крыла $-4,0$ см; ширина шеи - 0,6 см; высота шеи - 1,4 см; ширина тулова - 1,1 см; максимальная ширина тулова - 1,9 см; размах плеч - 4,5 см (по внешнему контуру). Сохранность удовлетворительная. Требуется первичная консервация.

Фигура 13 (рис. 2,4).

Литье, бронза. Часть фигуры оформлена под голову птицы, которая имеет клюв и глаза. На правом и левом плече имеются три и две волны, которые изображают оперение. К тому же на левом крыле имеется очень четкое стилизованное изображение перьев в виде семи объемных валиков. Крылья подходят к тулову по дуге, близкой к прямому углу. На тулове расположен объемный орнамент в виде двуреечного креста, лапы стилизуются под две «жемчужины» и отчетливо выражено хвостовое оперение. Размеры изделия: длина $-6,7$ см; длина левого крыла - 3,3 см; длина правого крыла - 3,2 см; размер головы $1,0 \times 1,0 \times 0,7$ см; ширина тулова - 1,0 см; максимальная ширина тулова $-1,8$ см; размер орнамента занимает всю поверхность; размах плеч $-2,5$ см. Сохранность удовлетворительная. Требуется первичная консервация.

Фигура 14 (рис. 2,8).

Литье, бронза. Тулово расширяется к нижней части. По лицевой стороне изделия нанесен объемный, рельефный орнамент в виде «согнутых лап хищной птицы». Крылья и плечи образуют между собой прямой угол, на левом крыле имеется две волны, которые обозначают перья. Такая же, но только одна волна имеется на правом крыле. Возможно, неровности обработки тулова также символизируют стилизованное оперение. Размеры изделия: длина $-7,0$ см; длина левого крыла $-4,0$ см; длина правого крыла - 4,1 см; ширина шеи 0,6 см; высота шеи - 1,0 см; ширина тулова 0,9 см; максимальная ширина тулова $-1,8$ см; размер орнамента - 1,5 см; размах плеч 2,5 см (4,0 см по внешнему контуру). Сохранность удовлетворительная. Требуется первичная консервация.

Фигура 15 (рис. 2,9).

Литье, бронза, ковка. Это последняя фигура из «кунашакского» клада. Она представляет фрагмент хвостовой части орнитоморфа. Имеет практически треугольную форму, орнаменты отсутствуют. Верхняя часть изделия согнута и прокована. Размеры: высота $-4,5$ см, ширина $-2,4$ см. Судя по простоте изготовления и заковке по закраине, вполне возможно этот фрагмент является современной копией с древнего изделия.

В 0,5 м от местонахождения описанного клада орнитоморфов был обнаружен бронзовый трехлопастной со скрытой втулкой наконечник стрелы. Наконечник имеет треугольную головку. Размеры наконечника составили: длина пера $-2,3$ см; ширина лопасти у основания - 0,7 см; диаметр втулки - 0,3 см; глубина втулки - 0,9 см (рис. 2,10). Нахождение этого наконечника позволяет относительно точно датировать клад орнитоморфов. Согласно разработанной типологии и хронологии раннесарматских стрел М.Г. Мошковой рассматриваемый наконечник стрелы относится к типу XIII и может датироваться в пределах IV-III вв. до н.э. [Мошкова, 1962, рис. 28, 20б, 24]. Скорее всего, «клад» может быть датирован в этих же хронологических рамках.

Фигура 16 (рис. 2,5,6).

Литье, бронза. Случайная находка. Крылья короткие, ластовидные, средней ширины, подходят к тулову по дуге. На лицевой и тыльной стороне имеются объемные орнаменты. На лицевой стороне отчетливо просматривается грудка птицы, а также горизонтальный валик, отделяющий широкий веерообразный (треугольный) хвост. От валика, в низ хвоста отходят пять линий, которые имитируют хвостовое оперение. На тыльной стороне, по центру фигуры, имеется объемное изображение «креста». Чуть ниже его - три горизонтальных валика, имитирующие скелет орнитоморфа. От нижнего валика отходят линии, расположенные «елочкой», имитируя хвостовое опе- 
рение. Размеры изделия: длина - 6,2 см; длина левого крыла $-2,0$ см; длина правого крыла - 2,0 см; ширина шеи - 0,9 см; высота шеи 0,4 см; ширина тулова $-0,9$ см; максимальная ширина тулова $-2,4$ см; размах плеч 3,1 см. Сохранность удовлетворительная. Требуется первичная консервация.

Фигура 17 (рис. 2,7).

Литье, бронза. Фигура сломана и состоит из двух фрагментов. Случайная находка. Орнитоморф имеет хорошо выраженную голову птицы, невысокую шею, короткие дуговидные крылья. Левое крыло обломано, правое имеет ластовидную форму. Хвост веерообразный (треугольный). На лицевой стороне орнамент, состоящий из горизонтальной и пяти вертикальных отходящих вниз линий, обозначающий оперение хвоста. На тыльной стороне фигуры сохранилась петелька крепления и орнамент из трех горизонтальных валиков, имитирующих скелет. Размеры изделия: длина $-6,0$ см; длина левого крыла - 1,2 см; длина правого крыла $-2,0$ см; ширина шеи 0,9 см; высота шеи - 0,3 см; ширина тулова 0,6 см; максимальная ширина тулова $-2,4$ см; размах плеч $-3,0$ см. Сохранность удовлетворительная. Требуется первичная консервация и реставрация изделия.

Фигура 18 (рис. 2,8).

Литье, бронза. Фрагмент изделия. От фигурки сохранился только хвост орнитоморфа. Треугольный по форме хвост с объемным орнаментом в виде горизонтального валика и отходящих от него трех вертикальных валиков, которые имитируют хвостовое оперение. Размеры составили в длину 2,3 см, при максимальном расширении хвоста в 2,1 см.

Все орнитоморфные фигуры клада можно разделить на несколько групп по форме крыльев и форме хвоста. За основу группировки мы взяли систему группирования изделий такого рода, предложенную Ю.П. Чемякиным [Чемякин, 2016, с. 127].

Группу I составили фигуры орнитоморфов $1,7,9$, которые имеют узкие ластовидные расправленные крылья, согнутые под прямым углом, и прямой хвост. К тому же у фигур 1 и 9 отсутствует голова и практически не оформлено плечо правого крыла (рис. 1,1-3).

В группу II вошли орнитоморфные фигуры под номерами 2, 3, 4, 10, 14. Объединяю- щим признаком выступил критерий - оформление (точнее не оформление) головы. На всех пяти фигурах в хвостовой части имеется одинаковый орнамент, имитирующий «лапы и когти хищной птицы». У фигурок широкие ластовидные крылья с изображением оперения в виде «волны». Крылья расправлены под прямым углом, хвост округлый (вееровидный) (рис. 1,4-8).

Группа III представлена двумя «птицевидными» фигурами - 5 и 8 . Их объединяют в единую группу высокая шея, широкие ластовидные дугообразные крылья и прямой хвост. На фигурках имеется орнамент в виде 5 и 4 горизонтальных валиков, которые обозначают скелет птицы (рис. 1,9,10).

В группе IV оказались два орнитоморфных изделия - 6 и 11. Признаки, по которым они составили единую группу, следующие: средней высоты шея с обработанным литником, расправленные под прямым углом ластовидные крылья. К тому же на фигуpe 11 отчетливо видно изображение оперения (рис. 2,2,3).

На наш взгляд, образец 12 является промежуточным между фигурами, которые входят в группы III и IV. Этот идол имеет правое дуговидное крыло и левое расправленное под прямым углом. Относительно высокую шею с чуть обработанным литником под голову птицы. Фигура имеет прямой хвост. Отличительной особенностью является наличие трех «шипов», повидимому, обозначающих оперение (рис. 2,1).

Группу V составила одна орнитоморфная фигура 13. Эта единственная фигура в кладе, которая имеет отчетливо выраженную голову и клюв, ластовидные крылья под прямым углом, орнаментацию по хвосту и крыльям (рис. 2,4).

Группу VI составили орнитоморфы, которые были обнаружены в фондах ЦИКНЧ. Это фигуры 15, 17, 18. От фигур 15, 18 сохранился только хвост, фигура 17 сломана пополам. Эти фигуры объединяют в одну группу ярко выраженный треугольный хвост и орнамент, имитирующий оперение хвоста (рис. 2,7-9).

Фигура 16 стоит особняком. Наличие литника и дуговидных, ластообразных крыльев ставит этот орнитоморф между фигурами групп II и III, сложный объемный орнамент 
сближает с орнитоморфом из группы VI (рис. 2,5,6).

По всем признакам выделенные группы соответствуют орнитоморфной металлопластике, характерной для памятников иткульской археологической культуры VII-III вв. до н.э. Относительно прямые аналогии «птицеголовым идолам» из фондов музея археологии и этнографии ЧелГУ и ЦИКНЧ можно найти в изделиях мелкой металлопластики из памятников и святилищ Среднего Урала.

Описанные предметы кунашакского клада и единичные находки орнитоморфов являются не единственными находками на территории распространения памятников иткульской археологической культуры. По последней информации, клады очень часто встречаются в Полевском районе Свердловской области. Так, в 2015 г. 10 орнитоморфов обнаружены «черными» копателями в окрестностях г. Полевской [Гинц, 2018, с. 203]. За двадцать лет до этой находки в районе Гумешек обнаружен клад, в который входили орнитоморф и бронзовый котел [Мальгина, 2015, с. 1]. В 1940 г. на Азовгоре было обнаружено 24 орнитоморфа, которые были первоначально опубликованы в 1949 г. Н.Н. Бортвиным, а переопубликованы с дополнениями Ю.П. Чемякиным и С.В. Кузьминых в 2011 году [Бортвин, 1949, с. 118-124; Чемякин, Кузьминых, 2011, табл. 5, 6].

Из известных находок подобных «птицеголовых идолов» южно-уральский клад орни- томорфов является самым крупным в системе территориального распространения ареала памятников иткульской культуры в Челябинской области. Самой же южной находкой можно считать случайную находку на местонахождении Коркино IV в 1975 году [Чемякин, 2006, с. 71, рис. 1]. Также известны находки «птицеголовых идолов» на озере Куяш, близ с. Огневское [Чемякин, 2014, табл. 8,10,11,1419], пара случайных находок происходит из района г. Касли.

В пределах лесостепной и предгорной зон Южного Урала находки так называемых «птицеголовых идолов» весьма редки. Публикуемые в настоящей статье фигурки орнитоморфов оказались в фондах музея ЧелГУ и ЦИКНЧ разными путями. К сожалению, мы не знаем всех обстоятельств их обнаружения, с какого конкретного места они происходят. Нам известно, что большинство орнитоморфов, которые попадают в поле зрения археолога, как правило, происходят из грабительских раскопок. Скорее всего, происхождение и клада, и отдельных находок постигла такая же участь. Обычно клады обнаруживались на каких-то культовых священных или производственных для иткульских металлургов местах: горы, месторождения (Азов-гора, Гумешки, гора Караульная и др.). И, скорее всего, представленный в статье клад происходил с одного из подобных мест. 
И.Э. Любчанский, В.И. Юрин. «Птицеголовые идолы» из фондов Музея археологии и этнографии

\section{ИЛЛЮСТРАЦИИ}

Группа I
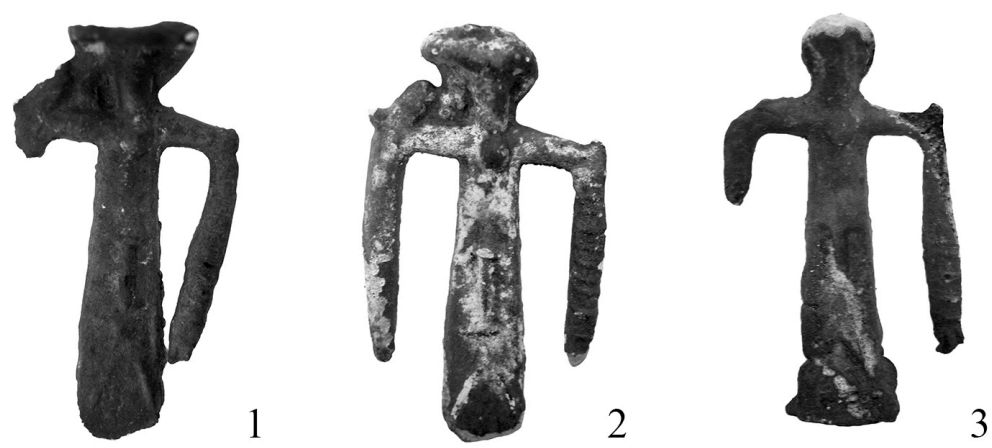

Группа II

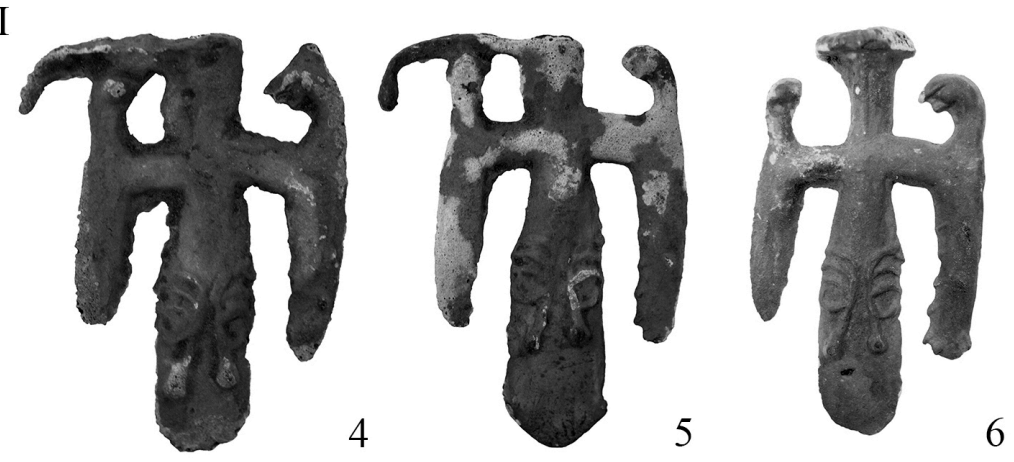

6

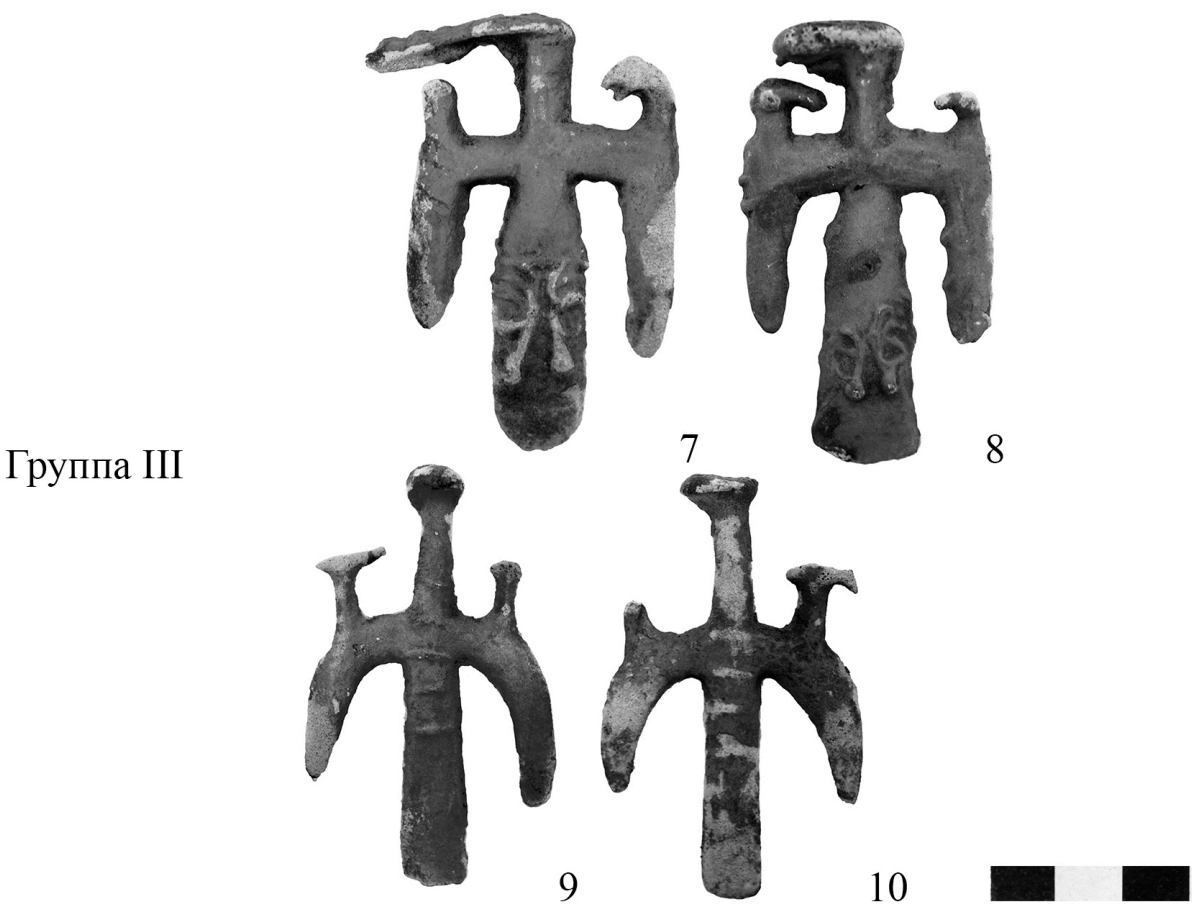

Рис. 1. Кунашакский «клад»:

Зооморфы группы I: 1 - фигура $1 ; 2$ - фигура 9; 3 - фигура 7.

Зооморфы группы II: 4 - фигура 2; 5 - фигура $3 ; 6$ - фигура 4; 7 - фигура $10 ; 8$ - фигура 14.

Зооморфы группы III: 9 - фигура 5; 10 - фигура 8. 1-10-бронза

Fig. 1. Kunashakskiy "hoard":

Zoomorphs of group I: 1 - figure 1;2 - figure 9; 3 - figure 7 .

Zoomorphs of group II: 4 - figure 2; 5 - figure 3; 6 - figure $4 ; 7$ - figure 10;8 - figure 14 .

Zoomorphs of group III: 9 - figure $5 ; 10$ - figure $8.1-10$ - bronze 
Переходная фигура 12

Группа IV
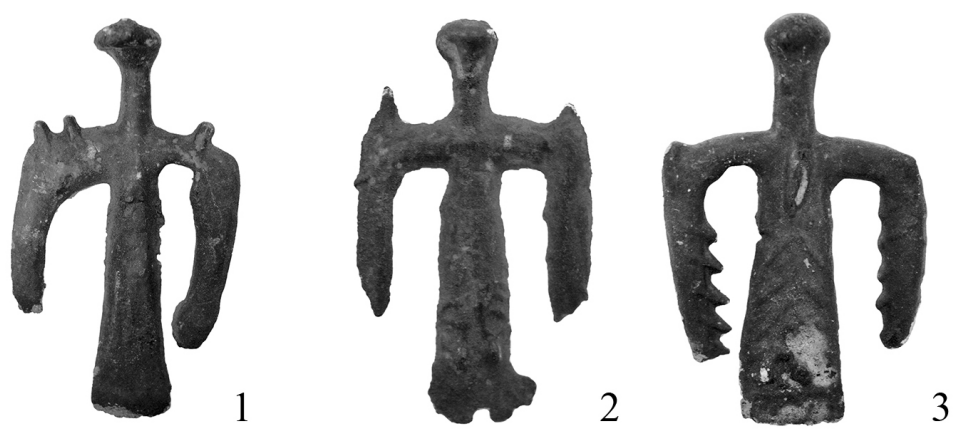

Группа V

Фигура 16 (переходная)
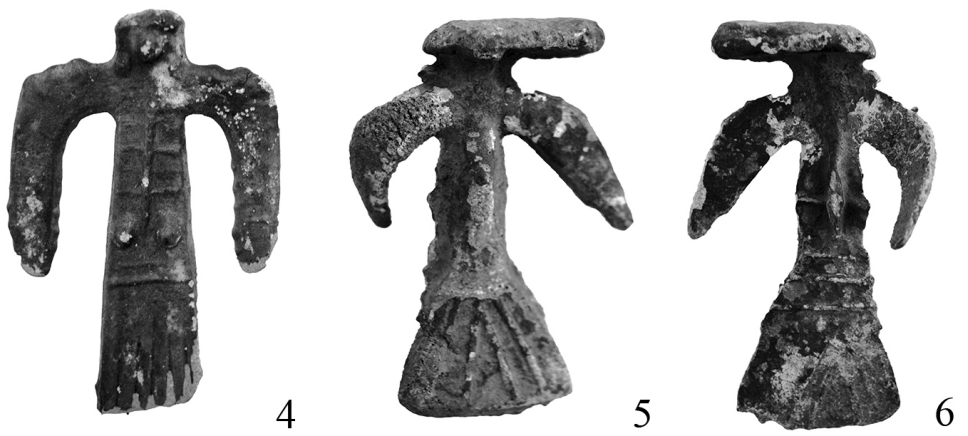

Группа VI
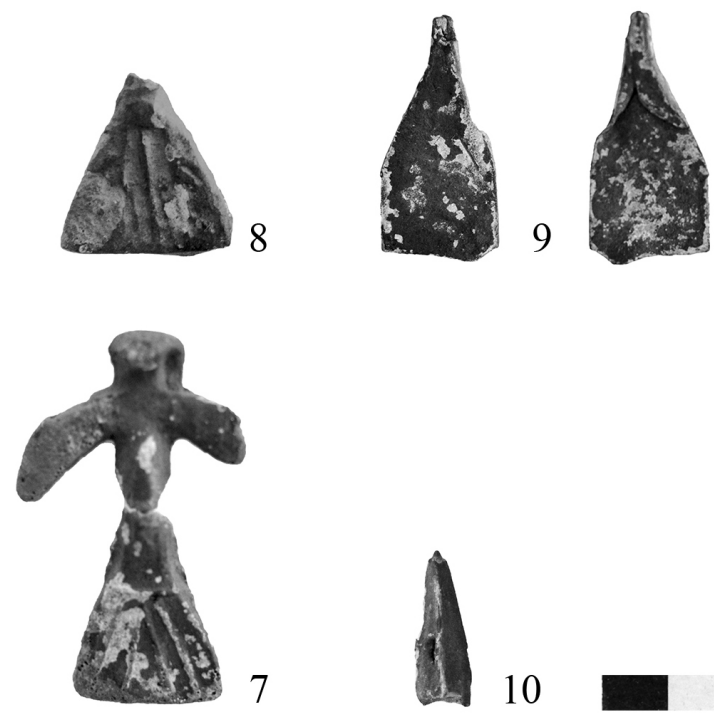

Рис. 2. Кунашакский «клад»:

1 - переходная фигура 12. Зооморфы группы IV и группы V: 2 - фигура 6; 3 - фигура 11; 4 - фигура 13. Зооморфы группы VI: 5, 6- фигура 16 переходная; 7 - фигура 17; 8 - фрагмент фигуры 18;

9 - фигура 15 (копия); 10 - наконечник стрелы. $1-10$ - бронза

Fig. 2. Kunashakskiy "hoard":

1 - transitional figure 12. Zoomorphs of group IV and group V: 2 - figure $6 ; 3$ - figure $11 ; 4$ - figure 13.

Zoomorphs of group VI: 5, 6 - transitional figure 16; 7 - figure 17; 8 - fragment of figure 18;

9 - figure 15 (copy); 10 - arrowhead. $1-10$ - bronze 


\section{СПИСОК ЛИТЕРАТУРЫ}

Бортвин Н. Н., 1949. Находка на горе Азов на Урале // Краткие сообщения института истории материальной культуры. Вып. XXV. М. ; Л. : Изд-во АН СССР. С. 118-124.

Гинц К. Э., 2018. Новый клад птицевидных идолов иткульской культуры // L Урало-Поволжская археологическая конференция студентов и молодых ученых : материалы Всерос. (с междунар. участием) конф., г. Самара, 0104 февр. 2018 г. Самара : Изд-во Самар. ун-та. C. 203-206.

Мальгина Л., 2015. Куда уйдет клад? В Полевском обнаружили бронзовых идолов иткульской культуры // Уральский рабочий. 16 окт. № 200 (28859). C. 1.

Мошкова М. Г., 1962. О раннесарматских втульчатых стрелах // Краткие сообщения институга археологии. № 89. М. : Изд-во АН СССР. C. $77-82$.

Чемякин Ю. П., 2006. Случайная находка в окрестностях Коркино // Пятые Берсовские чтения : сб. науч. ст. Екатеринбург : КВАДРАТ. С. $71-77$.

Чемякин Ю. П., 2014. Иткульские древности из грабительских раскопок // Проблемы сохранения и использования культурного наследия: история, методы и проблемы археологических исследований. Екатеринбург : Магеллан. С. 207-211.

Чемякин Ю. П., 2016. Культовая металлопластика иткульской культуры // XV Бадеровские чтения по археологии Урала и Поволжья : материалы Всерос. науч.-практ. конф. Пермь : Изд-во ПГНИУ. С. 126-135.

Чемякин Ю. П., Кузьминых С. В., 2011. Металлические орнитоморфные изображения раннего железного века Восточной Европы, Урала и Западной Сибири (лесная и лесостепная зоны) // Тверской археологический сборник. Вып. 8, т. II : материалы IV Твер. археол. конф. и 12-го заседания науч.-метод. семинара «Тверская земля и сопредельные территории в древности». Тверь : Триада. С. 43-74.

\section{REFERENCES}

Bortvin N.N., 1949. The finding on the Mountain of Azov in the Urals. Kratkie soobshheniya instituta istorii materialnoy kultury, iss. XXV. Moscow; Leningrad, AS USSR, pp. 118-124. (in Russian).

Ginc K.E., 2018. Newhoard of bird-like idols of Itkul culture. L Uralo-Povolzhskaya arheologicheskaya konferenciya studentov $i$ molodyh uchenyh: materialy Vseros. (s mezhdunar. uchastiem) konf., g. Samara, 01-04fevr. 2018 g. Samara, Izd-voSamar. un-ta, pp. 203-206. (in Russian).

Malgina L., 2015. Where will the hoard go? In Polevsky found bronze idols of Itkul culture. Uralskiy rabochiy, 16 okt., no. 200 (28859), p. 1. (in Russian).

Moshkova M.G., 1962. About Early-Sarmatian Arrow with Socket. Kratkie soobshheniya instituta arkheologii, no. 89. Moscow, AS USSR, pp. 7782. (in Russian).

Chemyakin Yu.P., 2006. An Accidental Finding in the Vicinity of Korkino. Pyatye Bersovskie Chteniya: sb. nauch. st. Ekaterinburg, KVADRAT Publ., pp. 71-77. (in Russian).

Chemyakin Yu.P., 2014. Itkul Antiquities from Looted Burials. Problemy sohraneniya i ispolzovaniya kulturnogo naslediya: istoriya, metody $i$ problemy arkheologicheskih issledovaniy. Ekaterinburg, Magellan Publ., pp. 207-211. (in Russian).

Chemyakin Yu.P., 2016. Cult Metal Plastic of Itkul Culture. $X V$ Baderovskie chteniya po arkheologii Urala i Povolzhiya: materaly Vseros. nauch.-prakt. konf. Perm, PSU, pp. 126135. (in Russian).

Chemyakin Yu.P., Kuzminih S.V., 2011. Metal Ornithomorphic Images of the Early Iron Age of Eastern Europe, the Urals and Western Siberia (Forest and Forest-Steppe Zones). Tverskoy arkheologicheskiiy sbornik, iss. 8, vol. II: materialy IV Tver. arkheol. konf. i 12-go zasedaniya nauch.-metod. seminara «Tverskaya zemlya $i$ sopredelnye territorii $v$ drevnosti». Tver, Triada Publ., pp. 43-74. (in Russian).

\section{Information about the Authors}

Ilya E. Liubchanskiy, Candidate of Sciences (History), Associate Professor, Scientific Secretary, Center of Historical and Cultural Heritage of Chelyabinsk, Svobody St., 60, 454081 Chelyabinsk, Russian Federation, hunns@yandex.ru, https://orcid.org/0000-0002-8824-3466

Vladimir I. Yurin, Senior Researcher, Center of Historical and Cultural Heritage of Chelyabinsk, Svobody St., 60, 454081 Chelyabinsk, Russian Federation, v_yurin@mail.ru, https://orcid.org/0000-00023259-5083 
I.E. Liubchanskiy, V.I. Yurin. Ornitomorphs of the Museum of Archaeology and Ethnography

\section{Информация об авторах}

Илья Эдуардович Любчанский, кандидат исторических наук, доцент, ученый секретарь, Центр историко-культурного наследия г. Челябинска, ул. Свободы, 60, 454081 г. Челябинск, Российская Федерация, hunns@yandex.ru, https://orcid.org/0000-0002-8824-3466

Владимир Иванович Юрин, старший научный сотрудник, Центр историко-культурного наследия г. Челябинска, ул. Свободы, 60, 454081 г. Челябинск, Российская Федерация, v_yurin@mail.ru, https://orcid.org/0000-0002-3259-5083 